\title{
Preparation and Characterization of Silanes Films to Protect Electrogalvanized Steel
}

\author{
Pablo R. Seré, Walter Egli, Alejandro R. Di Sarli, and Cecilia Deyá
}

\author{
(Submitted August 11, 2016; in revised form November 6, 2017; published online February 8, 2018)
}

\begin{abstract}
Silanes are an interesting alternative to chromate-based surface treatments for temporary protection of electrogalvanized steel. In this work, the protective behavior of 3-mercaptopropyltrimethoxysilane (MTMO), 3-aminopropyltriethoxysilane (AMEO), or 3-glycidoxypropyltrimethoxysilane (GLYMO) films applied on electrogalvanized automotive quality steel sheets has been studied. The silane coating morphology, composition, and porosity were characterized by scanning electron microscopy (SEM), energydispersive $x$-ray spectroscopy (EDS), $x$-ray fluorescence, immersion in copper sulfate, and cyclic voltammetry. The corrosion protection was evaluated by polarization curves, electrochemical noise measurements, electrochemical impedance spectrometry, and accelerated humidity chamber tests. The results showed that the silanes protect temporarily electrogalvanized steel from corrosion. MTMO forms a relatively thick and cracked film. AMEO and GLYMO films were so thin that they could not be observed by SEM but silicon was detected by EDS. MTMO provided good temporary protection, being an alternative to replace $\mathrm{Cr}$ (VI) as protector of electrogalvanized steel.
\end{abstract}

Keywords protective films electrogalvanized, silane, surface treatment

\section{Introduction}

Conversion coatings based on $\mathrm{Cr}(\mathrm{VI})$ have been used for many years to protect galvanized steel against corrosion during storage and use. Despite being very efficient, the $\mathrm{Cr}(\mathrm{VI})$ presents high toxicity and carcinogenicity (Ref 1), and therefore, it is necessary to find new alternatives, friendly with the environment and public health. As a result, in recent years, there have been numerous investigations on $\mathrm{Cr}$ (III), $\mathrm{Ce}(\mathrm{III})$, La(III)-based pretreatments with promising results (Ref 2-5). However, pretreatment solutions based on functionalized silanes appear to be one of the best alternatives (Ref 6,7). Although the silanes do not provide the self-repair ("selfhealing") effect offered by coatings containing $\mathrm{Cr}(\mathrm{VI})$, they are neither toxic nor pollutant, have good thermal stability and are resistant to erosion (Ref 8,9 ). The protective mechanism provided to the substrate by silane coatings is only by barrier effect (Ref 10-14). Therefore, the protection ability not only depends on the film porosity and thickness, but also on the silane nature. The presence of hydrophilic or hydrophobic chains in its structure can control the rate of water diffusion through the coating film (Ref 15). In addition, substrate characteristics such as roughness, metal structure, and impurity

Pablo R. Seré, and Cecilia Deyá, CIDEPINT, Centro de Investigación y Desarrollo en Tecnología de Pinturas (CICPBA-CONICET), Av. 52 entre 121 y 122 S/N, CP 1900 La Plata, Argentina; and Facultad de Ingeniería, UNLP, 1 y 47, CP 1900 La Plata, Argentina; Walter Egli and Alejandro R. Di Sarli, CIDEPINT, Centro de Investigación Desarrollo en Tecnología de Pinturas (CICPBA-CONICET), Av. 52 entre 121 y 122 S/N, CP 1900 La Plata, Argentina. Contact e-mail: c.deya@cidepint.gov.ar. should be considered since the silane/metal adhesion could be favored or decreased.

With regard to the organic functional groups (-R) present in the silane molecule, the most used in practice $(-\mathrm{SH},-\mathrm{OH}$, $\mathrm{CHOCH}_{2},-\mathrm{COOH},-\mathrm{NH}_{2}$ ) are selected based on the functional groups present in the protective paint. Often, an additional requirement is that the organic functional groups do not interact with the substrate surface in order to be available at the silane film outer surface and, as result, promote its adhesion to the paint layer. In these applications the most common pattern is the hydrolysis reaction of the silane molecule, i.e.,

$$
\begin{aligned}
\mathrm{R}- & \left(\mathrm{CH}_{2}\right) \mathrm{n}-\mathrm{Si}\left(\mathrm{OR}^{\prime}\right)_{3}+3 \mathrm{H}_{2} \mathrm{O} \rightarrow \mathrm{R}-\left(\mathrm{CH}_{2}\right) \mathrm{n}-\mathrm{Si}(\mathrm{OH})_{3} \\
& +3 \mathrm{R}^{\prime} \mathrm{OH},
\end{aligned}
$$

which leads to the formation of highly reactive silanol groups. The silanol groups react with the metal substrate oxides and hydroxides developing strong silicon-oxygen-metal bonds, Fig. 1 (Ref 16-18). It has been reported that films formed from these conversion treatments, applied on various metal substrates, enhance the adhesion to an organic coating (Ref 19-22). At present, there are different alternatives of commercial pretreatments based on organic functional silanes.

In this work, the behavior against corrosion of electrogalvanized steel automotive quality sheets (EG) pretreated with 3mercaptopropyltrimethoxysilane (MTMO), 3-aminopropyltriethoxysilane (AMEO), 3-glycidoxypropyltrimethoxysilane (GLYMO) or with a Cr(VI) solution was studied. EG samples without treatment were used as reference. The coatings porosity was evaluated by immersion in a copper sulfate solution and by cyclic voltammetry $(\mathrm{CV})$. The corrosion behavior was studied by performing polarization curves (PC), electrochemical noise measurements (ENM), electrochemical impedance spectroscopy (EIS), and samples exposed in the controlled humidity and temperature chamber (HC). The morphology of the coatings was evaluated by scanning electron microscopy (SEM), while their composition was analyzed by energy- 
dispersive $\mathrm{x}$-ray spectroscopy (EDS) and x-ray fluorescence (XRF).

\section{Materials and Methods}

\subsection{Samples Preparation}

Samples $(7.5 \mathrm{~cm} \times 10.0 \mathrm{~cm} \times 0.06 \mathrm{~cm})$ of commercial electrogalvanized steel automotive quality were prepared. Base steel SAE 1004 was used as substrate; the zinc coating thickness determined by gravimetry was $7 \mu \mathrm{m}$. All the samples were electrochemically cleaned by dipping in $10 \%(\mathrm{v} / \mathrm{v}) \mathrm{NaOH}$ solution. The applied current density was $0.12 \mathrm{~A} / \mathrm{cm}^{2}$, while the temperature was set at $40{ }^{\circ} \mathrm{C}$.

MTMO solution was prepared by adding $4 \% \mathrm{v} / \mathrm{v}$ of MTMO to a distilled water/methanol $(3 / 2 \mathrm{v} / \mathrm{v})$ solution; the $\mathrm{pH}$ was adjusted to 4 with acetic acid (Ref 18).

AMEO solution was prepared by adding $2 \% \mathrm{v} / \mathrm{v}$ of AMEO to a distilled water/isopropanol $(0.5 / 99.5 \mathrm{v} / \mathrm{v})$ solution; the $\mathrm{pH}$ was 9 (Ref 22).

GLYMO solution was prepared by adding $1 \% \mathrm{v} / \mathrm{v}$ of GLYMO in distilled water; the pH was 5 (Ref 23).

The solutions were mechanically stirred for $1 \mathrm{~h}$. Then, the samples were immersed in the silane solutions for $1 \mathrm{~min}$, dried

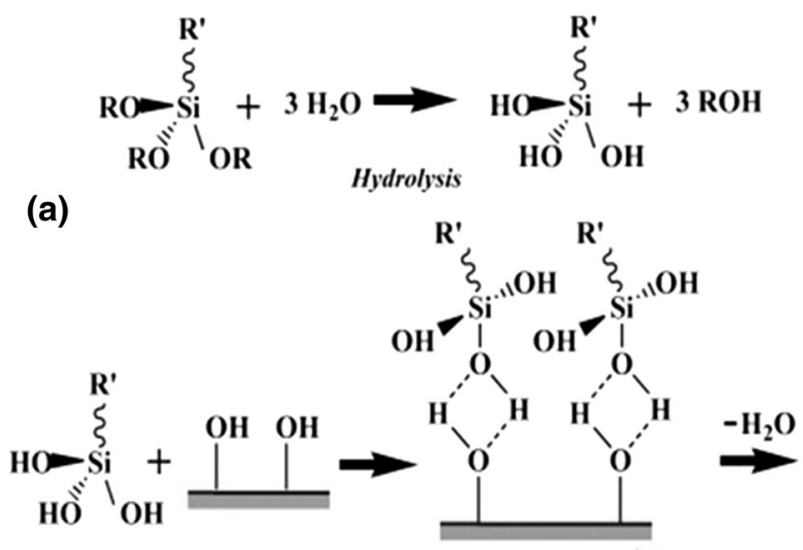

(b) Hydrogen-bonded adsorption

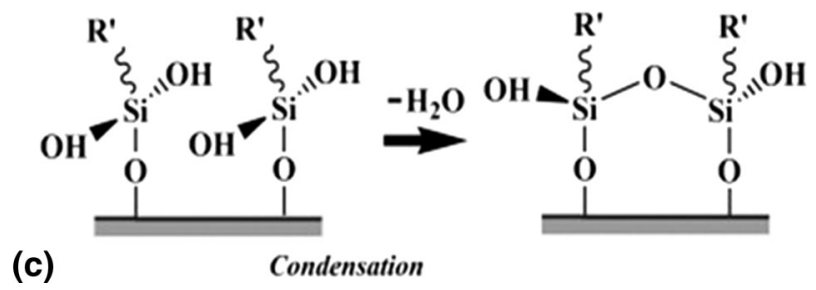

Fig. 1 Silane film formation stages: (a) hydrolysis, (b) adsorption process (c) condensation with hot air, and cured in an oven according to the operative conditions shown in Table 1.

Chromate treatment was applied by immersing the samples for $1 \mathrm{~min}$ in a solution of $2.2 \mathrm{~g} / \mathrm{L}$ of $\mathrm{K}_{2} \mathrm{Cr}_{2} \mathrm{O}_{7}$ at $22 \pm 1{ }^{\circ} \mathrm{C}$. Afterward, the samples (CrVI) were dried with hot air jet.

The silane solution preparation and curing conditions were chosen in order to obtain the better film protective properties according to references ( $\operatorname{Ref} 18,22,23)$.

\subsection{Samples Characterization}

Once cured, the obtained silane films were observed by SEM using a microscope Quanta $200^{\circledR}$ FEI electron detector Apollo 40 and by light optical microscopy (USB portable DigiView), while their composition was determined by EDS using a detector EDAX $^{\circledR}$. Furthermore, a coating composition analysis was performed using XRF.

The films porosity was evaluated by immersion in a copper sulfate solution, according to the ASTM A 239 standard and also by cyclic voltammetry (CV).

For the copper sulfate test, $36 \mathrm{~g}$ of $\mathrm{CuSO}_{4} \cdot 5 \mathrm{H}_{2} \mathrm{O}$ were dissolved in $100 \mathrm{~mL}$ of distilled $\mathrm{H}_{2} \mathrm{O}$, and the solution was saturated with $\mathrm{Cu}(\mathrm{OH})_{2}$ to neutralize. The samples were immersed for $10 \mathrm{~s}$ in the solution and then rinsed with distilled water. When the exposed $\mathrm{Zn}$ reacts with $\mathrm{Cu}^{+2}$, it gives $\mathrm{Cu}^{\circ}$ which is deposited on the surface revealing the temporary protective film pores. Thus, by visual observation and optical microscopy, the degree of the porosity of the films, a parameter related to the amount of electrochemically active zinc sites on which copper is deposited, can be assessed. In addition, CV was performed on an aerated borate solution $(35 \mathrm{~g} / \mathrm{L}$ $\mathrm{H}_{3} \mathrm{BO}_{3}+40 \mathrm{~g} / \mathrm{L} \mathrm{Na} \mathrm{Ba}_{4} \mathrm{O}_{7} \cdot 10 \mathrm{H}_{2} \mathrm{O}$ ) at $(22 \pm 1){ }^{\circ} \mathrm{C}$ (Ref 24, $25)$. The potential swept at a rate of $100 \mathrm{mV} / \mathrm{s}$ was performed from -1500 up to $-500 \mathrm{mV}$ versus saturated calomel electrode (SCE). In this electrolyte, the $\mathrm{CV}$ of the zinc electrode shows an anodic peak corresponding to dissolution followed by a passive region. The integration of this peak gives the anodic charge, which is proportional to the electrochemically active zinc area.

\subsection{Electrochemical Tests}

Potentiodynamic tests were performed in $0.05 \mathrm{~mol} / \mathrm{L} \mathrm{NaCl}$ solution at $(22 \pm 1){ }^{\circ} \mathrm{C}$. The speed and range of potential swept were $0.166 \mathrm{mV} / \mathrm{s}$ and $\pm 50 \mathrm{mV}$ from the open-circuit potential (OCP), respectively. The working electrode area was $1 \mathrm{~cm}^{2}$. A large area Pt mesh was used as counterelectrode and a SCE as reference. The corrosion current density $\left(J_{\text {corr }}\right)$ was obtained by linear regression of the $\mathrm{E}$ versus $\log (J)$ graph at potentials higher than $\pm 10 \mathrm{mV}$ from the OCP (Ref 26). Cyclic voltammetry and polarization curves were obtained with a Potentiostat/Galvanostat PAR $273 \mathrm{~A}^{\circledR}$ controlled by the CorrWare ${ }^{\circledR}$ software.

The electrochemical noise measurements were accomplished using as working electrodes two samples of the same material and area, and as reference a SCE. The exposed surface

Table 1 Silanes application and curing conditions

\begin{tabular}{lcccc}
\hline Silane & \% (v/v) & Immersion time, min & Curing time, min & Curing temperature, ${ }^{\circ} \mathbf{C}$ \\
\hline AMEO & 2 & 1 & 15 & 75 \\
MTMO & 4 & 1 & 10 & 80 \\
GLYMO & 1 & 1 & 60 & 93 \\
\hline
\end{tabular}


area of each working electrode was $38 \mathrm{~cm}^{2}$, and their edges were isolated with wax. These electrodes were connected through a low impedance resistance $(1.2 \Omega)$. The current noise was measured as the voltage fluctuation across this resistance. The three electrodes were immersed in $0.05 \mathrm{~mol} / \mathrm{L} \mathrm{NaCl}$ solution and the electrochemical cell placed in a Faraday cage. Data were acquired with a NICOLET 310 digital oscilloscope controlled by the 310RSWFT software. Adequate filtering was provided to eliminate undesirable signals like line signals (Ref 27-29). The measuring device sensitivity in the potential and current scales measurements was $100 \mu \mathrm{V}$ and $100 \mathrm{nA}$, respectively. The sampling frequency was $5 \mathrm{~Hz}$, which is commonly used to study corroding systems (Ref 27-29), and data were collected for $800 \mathrm{~s}$.

A statistical analysis of each data set was performed and the noise resistance $(\mathrm{Nr})$ calculated by using:

$$
\mathrm{Nr}=\delta E / \delta I
$$

where $\delta E$ and $\delta I$ are the potential and current dispersions, respectively (Ref 30,31 ).

To carry out the impedance measurements, a cylindrical clamp-on acrylic cell was positioned on the samples, defining a surface area of $15.9 \mathrm{~cm}^{2}$ with a rubber o'ring. A Pt mesh was used as counterelectrode and a SCE as reference. The samples were exposed to $0.05 \mathrm{~mol} / \mathrm{L} \mathrm{NaCl}$ solution at $(22 \pm 1){ }^{\circ} \mathrm{C}$, and the EIS measurements were performed for $32 \mathrm{~h}$ of immersion. Impedance spectra were obtained in the potentiostatic mode at the OCP using a sinusoidal signal, amplitude $15 \mathrm{mV}$ peak to peak, provided by a Solartron $1255 \mathrm{FRA}^{\circledR}$ coupled to a Potentiostat/Galvanostat Solartron $1286 \mathrm{EI}^{\circledR}$, and both controlled by the Zplot ${ }^{\circledR}$ software.

The temporary protection degree offered by each pretreatment was also evaluated by accelerated tests performed according to the ASTM D 2247 standard in a controlled humidity and temperature chamber.

\section{Results and Discussion}

\subsection{Coatings Characterization}

Films based on silanes are very thin (thickness $\approx 500 \mathrm{~nm}$ ). Furthermore, during the film polymerization internal stresses can occur causing defects (cracks, pores), a very important feature of these coating types as they can only protect the substrate by a physical barrier effect. In this regard, it has been reported that porosity increases with decrease in films thickness (Ref 32). Analyzed by SEM, MTMO film showed cracks and its thickness was estimated at about $500 \mathrm{~nm}$, Fig. 2. Even though the same analysis did not allow seeing AMEO and GLYMO films, silicon was detected by EDS and XRF in both cases but in a lower amount than in MTMO film, Fig. 3 and Table 2. This may indicate that AMEO and GLYMO films were thinner than the MTMO one. Chromate (CrVI) coating could not be seen by SEM but Cr was detected by XRF, Table 2 .

In EG, CrVI, AMEO, GLYMO and MTMO samples, the electrochemically active zinc area exposed to the solution containing $\mathrm{Cu}^{+2}$ was evaluated, Fig. 4. As seen, in EG samples, copper was deposited on the entire surface, certifying that $100 \%$ of the geometrical area was active zinc; the same deposition level was observed in GLYMO samples but, in this case, it reveals that the formed film was extremely porous. In
CrVI, AMEO, and MTMO samples, the copper was deposited only at sites where the barrier generated by the film was absent (i.e., pores and/or cracks).

$\mathrm{CV}$ of the EG samples exhibited an anodic peak (A) at approximately $-1.0 \mathrm{~V} /(\mathrm{SCE})$ followed by a passive region, Fig. 5. This peak corresponds to the formation of a $\mathrm{ZnO}$ and/or $\mathrm{Zn}(\mathrm{OH})_{2}$ film which blocks the active surface promoting the passivation process (Ref 24). Conversely, during cathodic polarization, the oxide-hydroxide film is reduced. The $\mathrm{H}_{2}$ evolution and $\mathrm{O}_{2}$ reduction reaction contributes to increase the current density in the cathodic peak (C) (Ref 33). The area under the curve of the anodic peak for each sample can be related to the active area exposed to the electrolyte. The relation between the active area of pretreated samples and the reference (EG) can be associated to the film porosity (FP) as follows (Ref 25):

$$
\mathrm{FP}=(A i / A o) \times 100,
$$

where $A i$ is the area under the anodic peak in the $(i)$ pretreated sample, and $A o$ is the area under the anodic peak in the EG sample. This technique is more sensitive than immersion in copper sulfate, allowing for the quantification of porosity differences among films.

As shown in Table 2, CrVI samples presented the lowest FP. This result is attributed to the presence of a chromate passive film which homogeneously covers the surface and avoids that the corrosion inducing chemicals (water, oxygen, ions) reach the underlying active Zn. Furthermore, GLYMO samples showed the highest FP indicating that the film developed by this silane is more porous than those formed by MTMO, AMEO, or CrVI. Such a conclusion correlates well with the obtained from the copper sulfate immersion test.

\subsection{Evaluation of the Temporary Protective Coatings}

Potentiodynamic assays showed that the four coatings protect the underlying zinc substrate since in all the coated samples the corrosion current density value (Jcorr) was less than the corresponding to the EG samples. The CrVI samples showed the best performance, Table 2 .

Surface passivation degree could be determined. In the case of an ideal non-porous coating covering the entire substrate surface, this would be completely isolated from the electrolyte. Therefore, the corrosion current density should be zero (total passivation, $100 \%$ ). If under defined experimental conditions, the corrosion current density for the $\mathrm{Zn} / \mathrm{Zn}^{+2}$ reaction has a reproducible value, and this latter can be used to determine the passivation degree of different silane films. The surface passivation degree (SPD\%) is defined as:

$$
\mathrm{SPD}=\left(1-J_{\text {corri }_{\mathrm{i}}} / J_{\text {corr }_{\mathrm{o}}}\right) \times 100,
$$

where $J \operatorname{corr}_{i}$ is the corrosion current density of the i-sample with passive film and $J_{\mathrm{corr}_{\mathrm{o}}}$ is the corrosion current density of the EG sample. SPD values for various passivation films are shown in Table 2. These results agree with those obtained in the CV experiences since the film with lower FP in this assay had the highest SPD, such is the case of CrVI samples. Furthermore, GLYMO samples had the opposite behavior, while the MTMO and AMEO samples had an intermediate performance.

During the electrochemical noise tests, all the samples presented almost constant corrosion potential values during the whole test. The exceptions were the AMEO samples which 


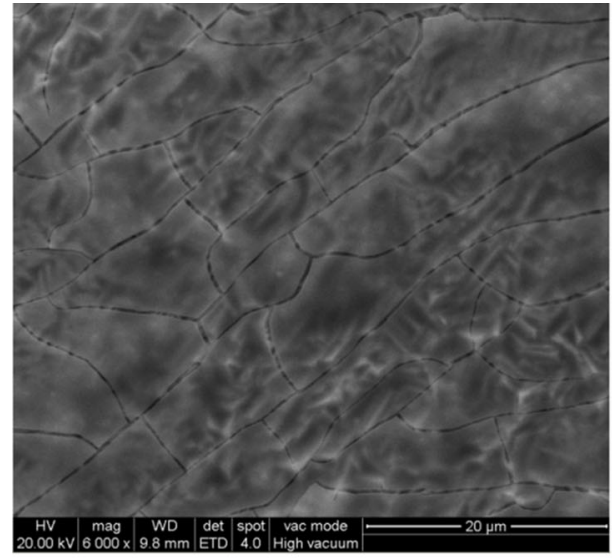

(a)

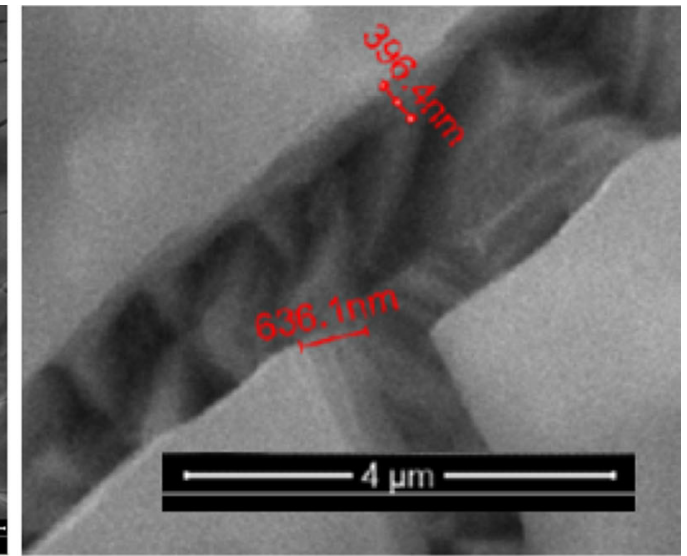

(b)

Fig. 2 SEM photograph of MTMO sample: (a) 6000X, (b) 24000X
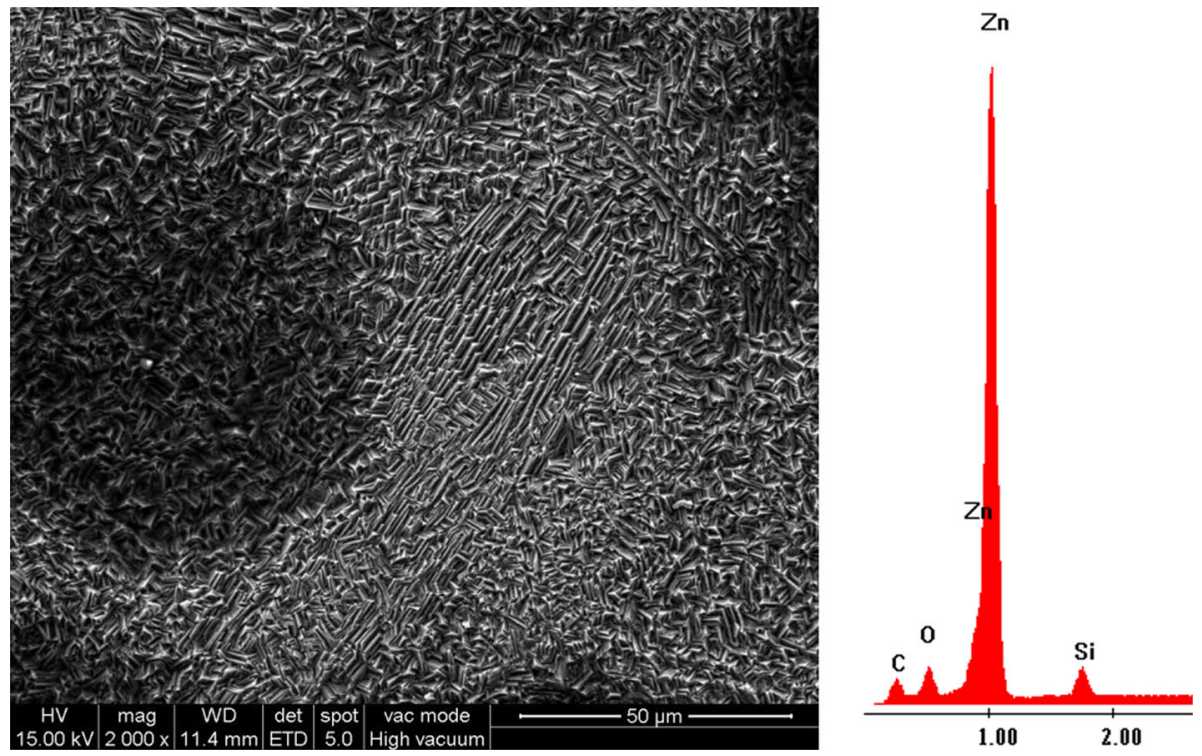

Fig. 3 SEM photograph of AMEO sample and part of the EDS spectrum

Table 2 XRF analysis of the conversion coatings composition, porosity (FP), corrosion current density ( $J_{\text {corr }}$ ), and surface passivation degree (SPD)

\begin{tabular}{|c|c|c|c|c|}
\hline Sample & Mass of element, wt.\% & FP, \% & $J_{\text {corrs }}, \mathrm{A} / \mathrm{cm}^{2}$ & DSP, $\%$ \\
\hline EG & $\ldots$ & 100 & $8.9 \times 10^{-5}$ & 0.0 \\
\hline CrVI & 0.28 of $\mathrm{Cr}$ & 1.69 & $6.7 \times 10^{-6}$ & 92.4 \\
\hline AMEO & 4.4 of $\mathrm{Si}$ & 25.00 & $5.0 \times 10^{-5}$ & 44.4 \\
\hline MTMO & 6.2 of $\mathrm{Si}$ & 12.50 & $4.1 \times 10^{-5}$ & 55.6 \\
\hline GLYMO & 2.7 of $\mathrm{Si}$ & 43.75 & $6.8 \times 10^{-5}$ & 22.2 \\
\hline
\end{tabular}

displayed a peak at $-0.8 \mathrm{~V}(\mathrm{SCE})$ at short time, Fig. 6. The coupling current and noise resistance gave values between \pm $0.4 \mathrm{~mA} / \mathrm{cm}^{2}$ and close to $2 \mathrm{k} \Omega \mathrm{cm}^{2}$, respectively. In the case of CrVI or GLYMO samples, the coupling current presented higher peak values during the test, indicating system instability and presence of surface heterogeneities.

In the impedance spectra the time constant at high frequencies is attributed to the resistive-capacitive properties afforded by the coating film. A phase angle plot showing a well-defined peak at these frequencies indicates an increase in the silane film cross-linking degree after the curing cycle (Ref 34-37). For MTMO samples, this peak was found at $10^{4} \mathrm{~Hz}$, while for the rest of layers was located at $10^{2} \mathrm{~Hz}$, Fig. 7. This fact indicates that the cross-linking degree developed in the layer was higher in MTMO samples than in the rest.

The impedance spectra of the studied electrogalvanized steel/coating systems were fitted by using equivalent electric circuits. An accurate physical description of the occurred 

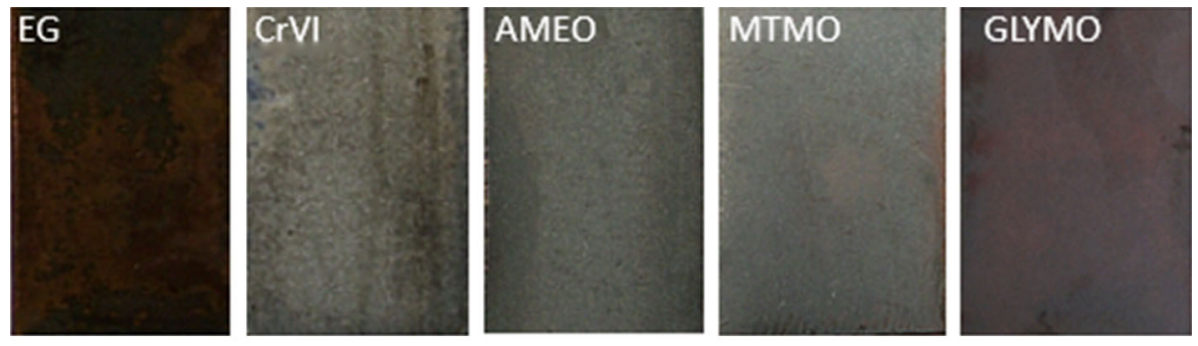

$7.5 \mathrm{~cm}$

Fig. 4 Photograph of the samples surface after the copper sulfate test

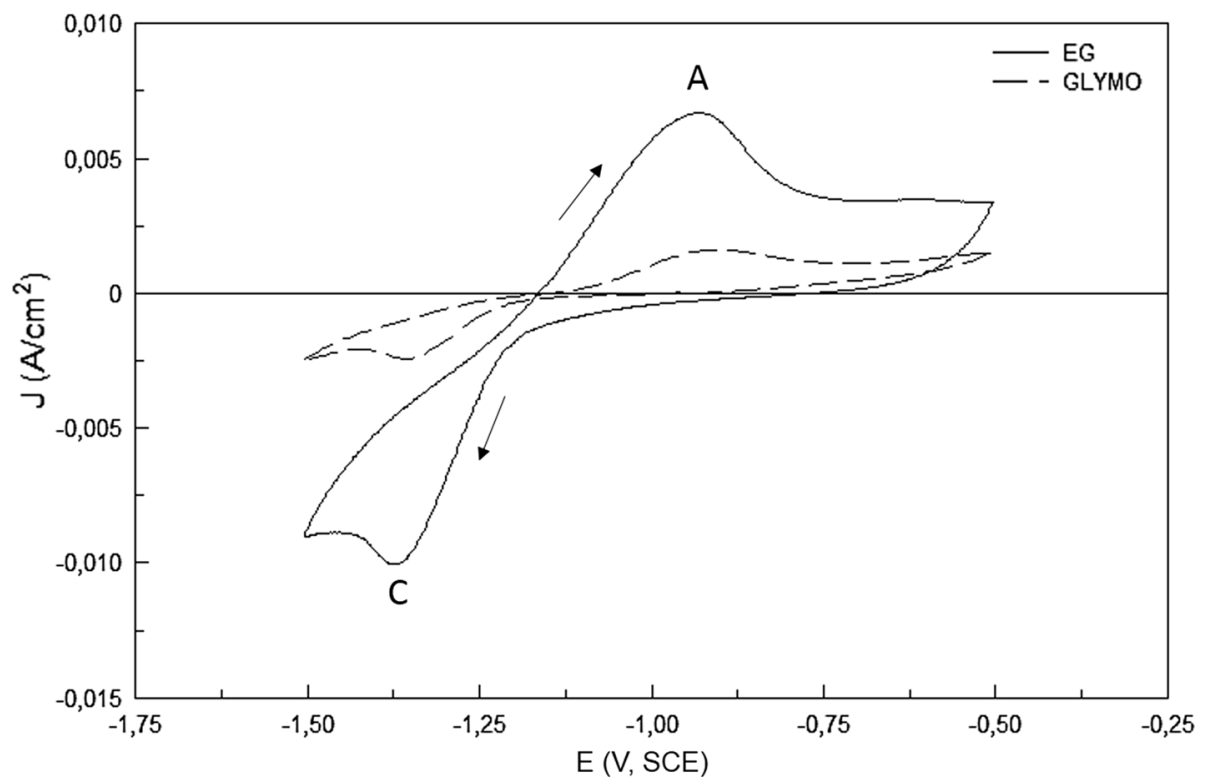

Fig. 5 CV of EG and GLYMO samples
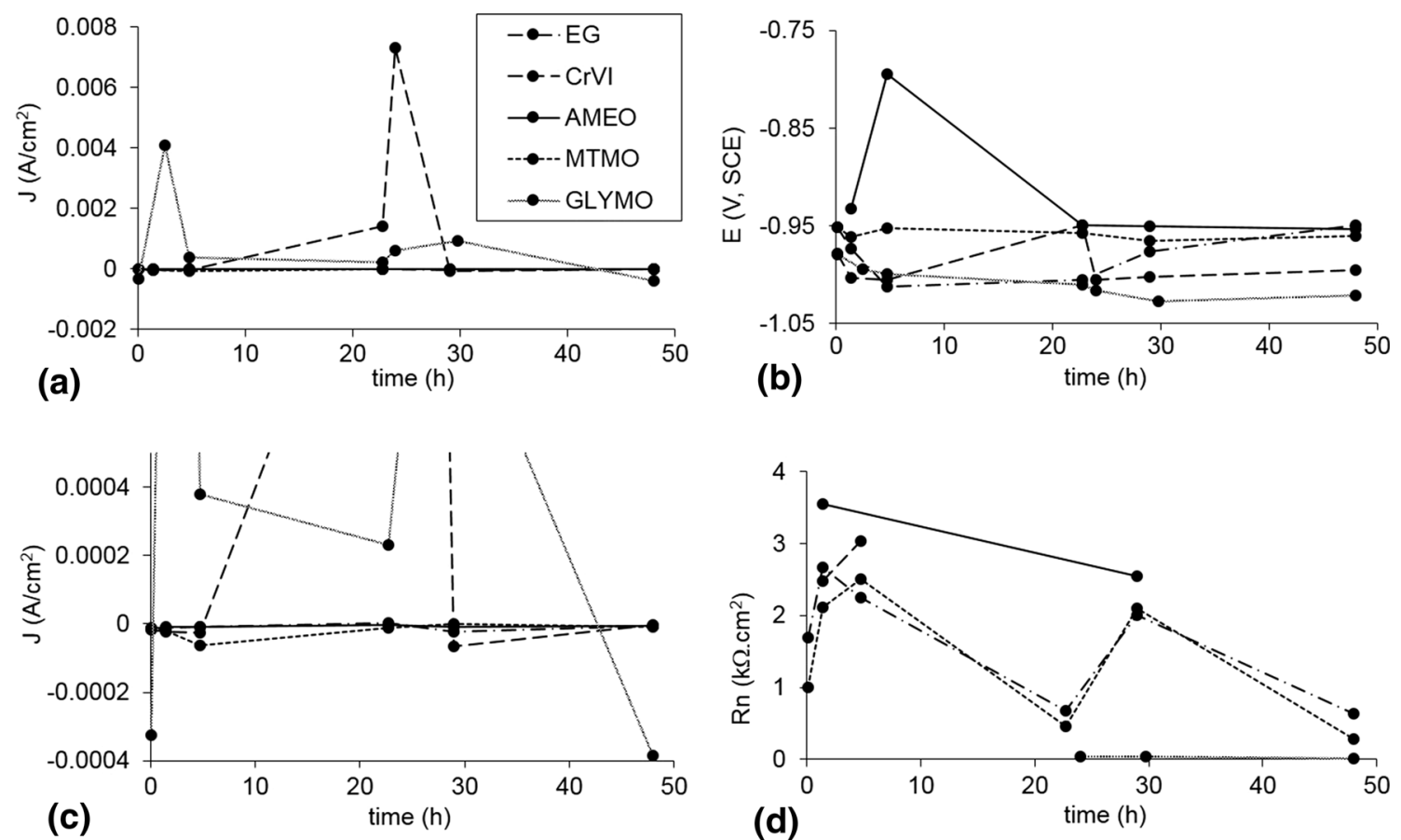

Fig. 6 Samples corrosion potential, coupling current, and noise resistance 

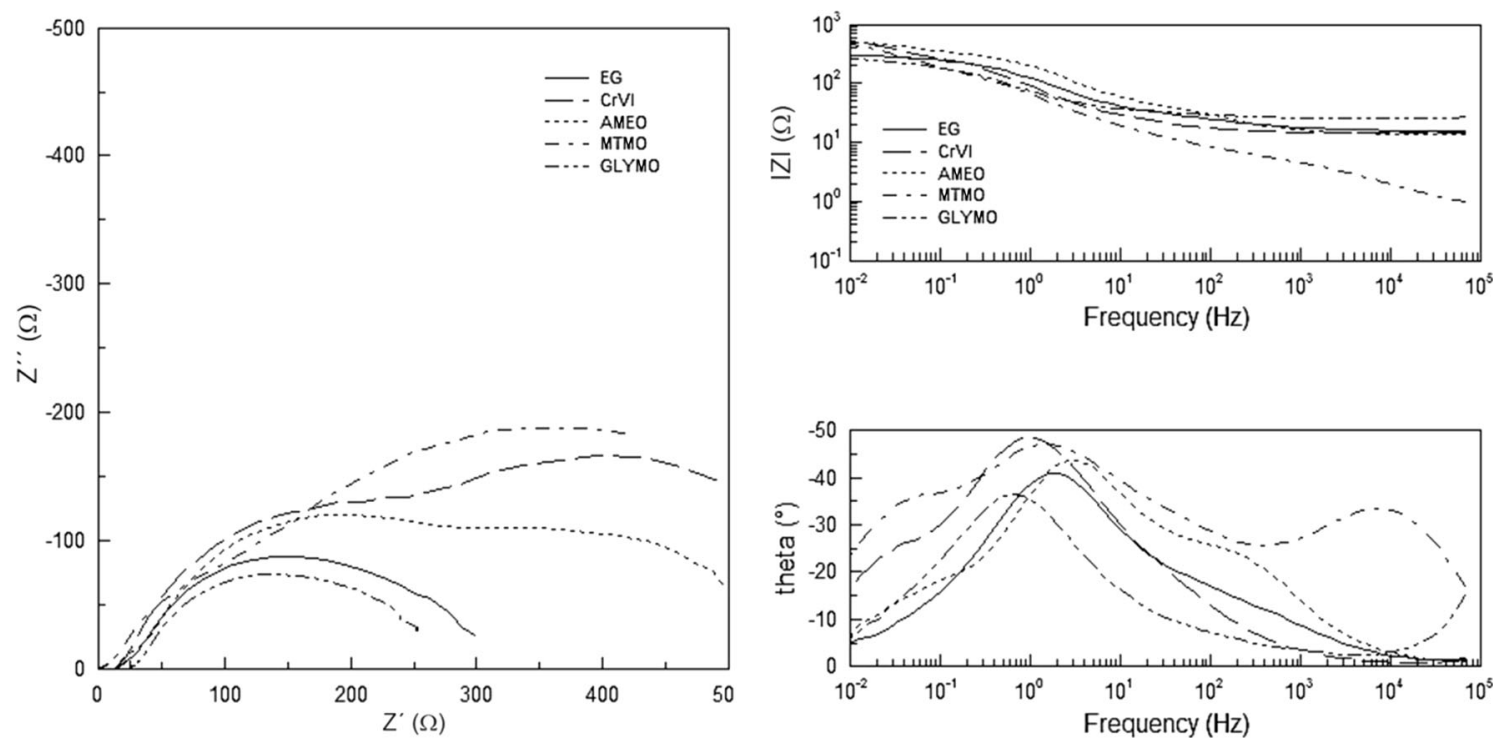

Fig. 7 Nyquist and Bode diagrams after $18 \mathrm{~h}$ of immersion in $0.5 \mathrm{~mol} / \mathrm{L} \mathrm{NaCl}$ solution

processes is not an easy task. In such cases, a standard deviation $\left(\chi^{2} \leq 5 \times 10^{-4}\right)$ was used as a criterion of acceptance, considering that the smaller this value, the closer the fit to the experimental data (Ref 38). The equivalent electric circuits and the experimental and simulated values evolution of the MTMO sample after $18 \mathrm{~h}$ of immersion in $\mathrm{NaCl}$ are shown in Fig. 8. In order to improve the adjustment quality, the dielectric capacitance (Ci) was replaced by a constant phase element $Q \mathrm{i}$, which describes more accurately the nonlinear behavior of these systems ( $\operatorname{Ref} 39$ ). The impedance of $Q$ is described by:

$$
Z Q=1 /(\omega)^{n} Y o
$$

where $\omega$ is the frequency, Yo is the pseudo-admittance of the system, and $n$ is a parameter that evaluates the distortion of a semicircle; when $n=1, Q$ describes an ideal capacitor while a 0.5 value represents a Warburg impedance with diffusional characteristics. These values are obtained using the corresponding equivalent circuit model (Ref 39).

In the case of CrVI, AMEO, and GLYMO samples, the best fit was obtained by considering two time constants, Fig. 8(a). The high-frequency constant (RfQf) represents the coating film resistive-capacitive characteristics. Rf symbolizes the coating resistance to the ionic flux, while the capacitance (Qf) is associated with the electrolyte permeability in the film. Pores and/or other defects in the conversion film generate paths through which the electrolyte can move toward the metallic substrate. As the electrolyte permeates through the coating, the tendency is an increase in the film capacitance (Qf), which is defined as:

$$
\mathrm{Qf}=\varepsilon_{\mathrm{r}} x \varepsilon_{\mathrm{o}} x A w / d,
$$

where $A w$ is the working electrode area $\left(\mathrm{m}^{2}\right), d$ the passive film thickness $(\mathrm{m}), \varepsilon_{o}$ the vacuum permittivity $\left(8.85 \times 10^{12} \mathrm{~F} /\right.$ $\mathrm{m}$ ), and $\varepsilon_{\mathrm{r}}$ is the relative permittivity (dielectric constant) of the passive film. For a dry and non-porous polymer the $\varepsilon_{r}$ value ranges between 3 and 4 . The value of the water dielectric constant is 80 , meaning that as the water permeates the passive film a significant increase in the Qf value occurs (Ref 7). This is a measure of the amount of water that the coating ab- sorbs (Ref 40). On the other hand, assuming that the $\mathrm{Rf}$ value depends on a given density of defects, and that these defects are cylindrical and go through the film, Rf can be defined as:

$$
R f=\rho(d / A p),
$$

where $\rho$ is the specific electrolyte resistivity in the pores $(\Omega \mathrm{m})$, and it is constant for a given electrolyte system, $d$ is the length of the cylindrical defects or coating thickness (m), and $A p$ is the coating pores area. Thus, for a given coating, $\mathrm{Rf}$ is inversely proportional to $A p$. Consequently, as the electrolyte enters into the coating through the pores and/or other defects, a drop in the Rf value occurs. Therefore, the evolution of this parameter is very important to evaluate the coating barrier performance in aqueous media.

The resistive and capacitive components (Rct, Qdl) of the time constant at low frequencies represent the corrosion process development at the substrate/coating film interface, Fig. 8. In this time constant, Rct represents the charge transfer resistance and Qdl the electrochemical double-layer capacitance. As mentioned above, in the case of MTMO samples the Bode diagram displayed three time constants, which are showed in the equivalent circuit model, Fig. 8(b). In the phase angle plot, peaks at high and medium frequencies are associated with the coating characteristics, and some authors claim that such peaks could be related to a film consisting of two layers ( $\mathrm{Rfl}$ and $\mathrm{Rf} 2$ ), so that the time constant defined at high frequency represents the response of the coating outer layer, while the defined at the medium range would correspond to the inner layer, nearer to the substrate (Ref 3 ). Other authors indicate that this split is due to heterogeneities and the existence of different cross-linking densities (dense or porous zones) (Ref 36, 37).

During the assay, the electrolyte permeation through the film increases due to increasing coating porosity and damage as it is hydrated. Furthermore, the corrosion products gathered at the coating/substrate interface produce delamination, causing the electrochemically active area to increase as well. However, the corrosion products gathering on active sites could seal some pores. Whereas the total resistance system (Rt) is the sum of the resistances composing the equivalent circuit, its fluctuation is attributed to the antagonism of these processes. As seen in 

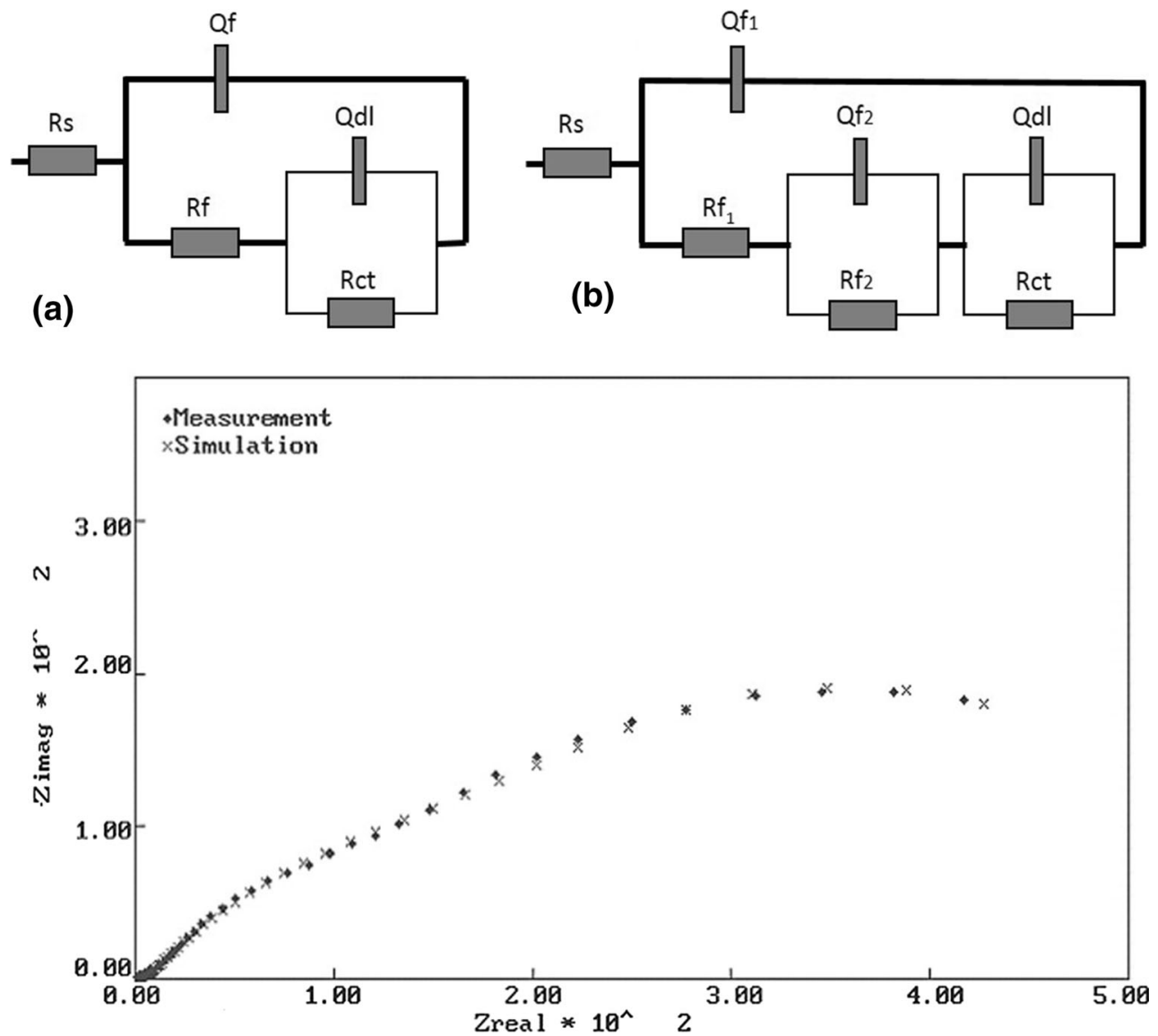

Fig. 8 Equivalent circuits representing the studied systems behavior and Nyquist plot of the MTMO sample, experimental and simulated data
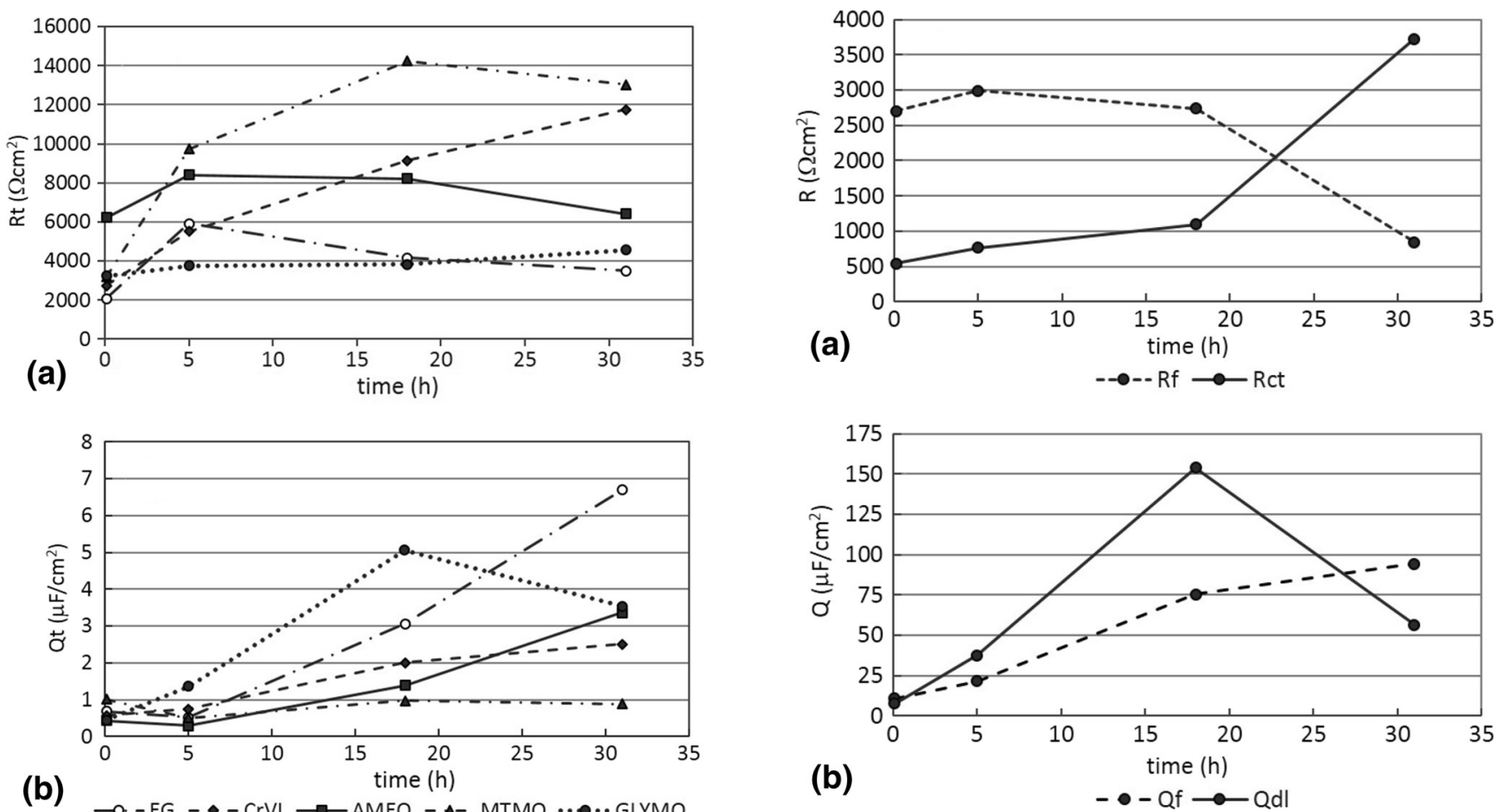

Fig. 9 Rt and Qt evolution

Fig. 10 Equivalent circuit components evolution of the GLYMO sample (a) Rf and Rct, (b) Qf and Qdl 

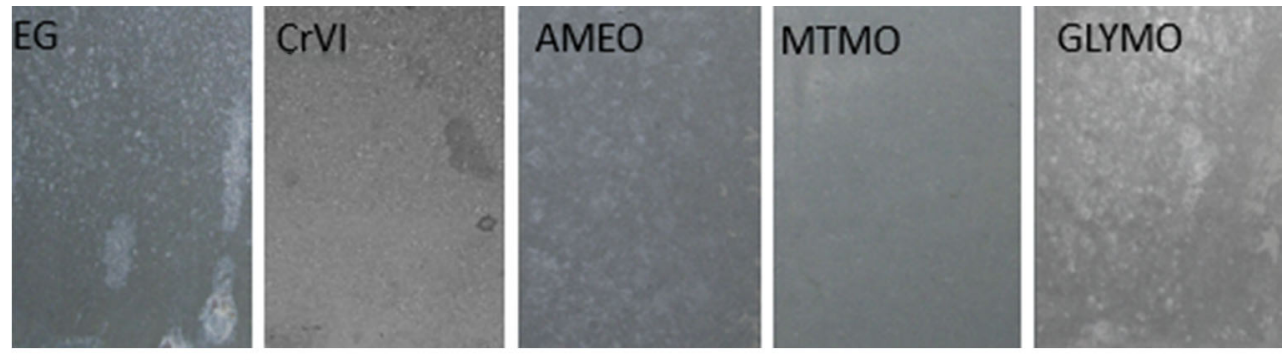

$7.5 \mathrm{~cm}$

Fig. 11 Photograph of the samples after $168 \mathrm{~h}$ of exposure to HC

Fig. 9, the Rt values in MTMO samples raised in the early assay stages but then fell slightly, indicating that the coating structure remains almost stable during the test. The electrolyte permeates through the film pores up to reach the substrate and creates the necessary and sufficient environmental conditions for the onset of corrosion. The corrosion products generated by this process seals the pores, and as a result, the Rt value grows. The major contribution to this increment is due to changes in the Rct values, which is scaled from 920 to $8070 \Omega \mathrm{cm}^{2}$ throughout the test. In AMEO samples, the Rt increased during the early immersion days because the coating withstands the electrolyte attack, but then its value decreased. This latter indicates that the coating structure is being damaged by the contact with the aggressive medium in such a way that the generation rate of new paths for electrolyte diffusion toward the substrate is greater than the blocking rate of active sites by the corrosion products. With regard to GLYMO samples, they remained stable throughout the test but with very low Rt values, Fig. 9. The $\mathrm{Rf}$ evolution of GLYMO shows that its value decreased throughout the test due to an increasing coating porosity but also that this behavior could be compensated by the Rct increment, Fig. 10(a). Such increment would be presumably caused by the blocking action of the corrosion products deposited on the substrate active sites. The Rt values corresponding to the CrVI samples display a growing tendency mainly by the Rct contribution. This latter is due not only to the self-healing effect produced by the unreacted $\mathrm{Cr}^{6+}$ ions, which can diffuse freely through the entire conversion layer, but also by the above-mentioned blocking of the zinc active sites.

The evolution of the coating capacitance (Qf) is associated with its capacity of withstand the electrolyte aggressiveness. Consequently, the increase in Qf can be explained by the increase in porosity. In turn, the increase in porosity increases the conductivity and water uptake value of the coating, which reduces the barrier properties. On the contrary, the decrease in this capacity is generally attributed not only to the blockage of the pores by the corrosion products - which reduces the area involved in the definition of that capacity - but also to the fact that their accumulation displaces the water of these pores and, therefore, contributes to decrease the dielectric constant affecting its value. For its part, the changes shown by the Qdl value in the different tested systems are associated not only with the just explained evolution of the barrier effect provided by each coating but also with the displayed by the corrosion products and their effects on the dimensions and dielectric behavior of the electrochemically active substrate area.

The accelerated corrosion tests in the $\mathrm{HC}$ revealed marked differences among the tested samples performance. After $168 \mathrm{~h}$ of exposure, EG samples showed a high percentage of its area covered with $\mathrm{Zn}(\mathrm{OH})_{2}$ (white dots). All the pretreatments provided some temporary protection degree, but the performance of AMEO and GLYMO samples was very poor since zinc corrosion products appeared prematurely. MTMO samples had the best performance, and no evidence of corrosion was observed after $168 \mathrm{~h}$ of exposure. Finally, CrVI samples exhibited a satisfactory performance although some points with protruding zinc corrosion products were observed, Fig. 11.

\section{Conclusions}

All the tested pretreatments applied on electrogalvanized steel showed some temporary protection degree.

According to the results of the short-term electrochemical tests (polarization curves and cyclic voltammetry), the CrVI coating was the most uniform and less active of the tested systems.

MTMO layer had lower porosity and higher thickness than the AMEO and GLYMO coatings. MTMO also showed very good performance as corrosion temporary protection in both the long-term immersion tests (EIS) and the humidity chamber, qualities that enabled it to be considered as an interesting alternative to replace the $\mathrm{Cr}(\mathrm{VI})$ as temporary protector of electrogalvanized steel sheet in the automotive and home appliances industries.

\section{Acknowledgments}

The authors gratefully acknowledge the Comisión de Investigaciones Científicas de la Provincia de Buenos Aires (CICPBA), the Universidad Nacional de La Plata (UNLP), and the Consejo Nacional de Investigaciones Científicas y Técnicas (CONICET) for the financial support to this research work. Besides, the authors thank Andres Campbell from Camsi-X for providing the silanes and the CONICET for the founding project PIP 0043.

\section{References}

1. U. S. P. H. Service, Toxicological Profile for Chromium No. ASTSDR/ TP-88/10, Agency for Toxic Substances, Public Health Service, 2010

2. M.G.S. Ferreira, R.G. Duarte, M.F. Montemor, and A.M.P. Simões, Silanes and Rare Earth Salts as Chromate Replacers for Pre-treatments on Galvanised Steel, Electrochim. Acta, 2004, 49, p 2927-2935

3. G. Kong, L. Liu, J. Lu, C. Che, and Z. Zhong, Corrosion Behavior of Lanthanum-Based Conversion Coating Modified with Citric Acid on 
Hot Dip Galvanized Steel in Aerated $1 \mathrm{M} \mathrm{NaCl}$ Solution, Corros. Sci., 2011, 53(4), p 1621-1626

4. M.F. Montemor, A.M. Simões, and M.G.S. Ferreira, Composition and Behaviour of Cerium Films on Galvanised Steel, Progr. Org. Coat., 2001, 43(4), p 274-281

5. X. Zhang, C. van den Bos, W.G. Sloof, A. Hovestad, H. Terryn, and J.H.W. de Wit, Comparison of the Morphology And Corrosion Performance of $\mathrm{Cr}(\mathrm{VI})-$ and $\mathrm{Cr}(\mathrm{III})$-Based Conversion Coatings on Zinc, Surf. Coat. Technol., 2005, 199(1), p 92-104

6. D. Zhu and W.J. van Ooij, Corrosion Protection of Metals by WaterBased Silane Mixtures of bis-[trimethoxysilylpropyl]amine and Vinyltriacetoxysilane, Progr. Org. Coat., 2004, 49(1), p 42-53

7. W.J. van Ooij, D. Zhu, M. Stacy, A. Seth, T. Mugada, J. Gandhi, and P. Puomi, Corrosion Protection Properties of Organofunctional Silanes-An Overview, Tsinghua Sci. Technol., 2005, 10(6), p 639-664

8. W.E.G. Hansal, S. Hansal, M. Pölzler, A. Kornherr, G. Zifferer, and G.E. Nauer, Investigation of Polysiloxane Coatings as Corrosion Inhibitors of Zinc Surfaces, Surf. Coat. Tech., 2006, 200(9), p 3056-3063

9. M.G.S. Ferreira, M.L. Zheludkevich, J. Tedim, and K.A. Yasakau, SelfHealing Nanocoatings for Corrosion Control, Woodhead Publishing Limited, Cambridge, 2012

10. B.C. Dave, X.K. Hu, Y. Devaraj, and S.K. Dhali, Sol-Gel Derived Corrosion-Protection Coatings, J. Sol-Gel Sci. Technol., 2004, 32(13), p 143-147

11. S. Ono, H. Tsuge, Y. Nishi, and S. Hirano, Improvment of Corrosion Resistance of Metals by an Environmentally Friendly Silica Coating Method, J. Sol-Gel Sci. Technol., 2004, 29(3), p 147-153

12. X.F. Yang, D.E. Tallman, V.J. Gelling, G.P. Bierwagen, L.S. Kasten, and J. Berg, Use of a Sol-Gel Conversion Coating for Aluminum Corrosion Protection, Surf. Coat. Technol., 2001, 140(1), p 44-50

13. J.H. Osborne, Observations on Chromate Conversion Coatings From a Sol-Gel Perspective, Progr. Org. Coat., 2001, 41(4), p 280-286

14. A. Conde, J. De Damborenea, A. Duran, and M. Menning, Protective Properties of a Sol-Gel Coating on Zinc Coated Steel, J. Sol-Gel Sci. Technol., 2006, 37, p 79-85

15. U. Eduok, R. Suleiman, M. Khaled, and R. Akid, Enhancing Water Repellency and Anticorrosion Properties of a Hybridsilica Coating on Mild Steel, Progr. Org. Coat., 2016, 93, p 97-108

16. U. Bexell, T.M. Grehk, M. Olsson, and U. Gelius, XPS and AES Characterization of Hydrolysed $\gamma$-mercaptopropyltrimethoxysilane Deposited on Al, Zn and Al-43.4Zn-1.6Si Alloy-Coated Steel, Surf. Interface Anal., 2004, 36(7), p 624-631

17. U. Bexell and M. Olsson, Time-of-Flight SIMS Characterization of Hydrolysed Organofunctional and Non-organofunctional Silanes Deposited on Al, Zn and Al-43.4Zn-1.6Si Alloy-Coated Steel, Surf. Interface Anal., 2003, 35(11), p 880-887

18. U. Bexell and T.M. Grehk, A Corrosion Study of Hot-Dip Galvanized Steel Sheet Pre-treated with $\gamma$-mercaptopropyltrimethoxysilane, Surf. Coat. Technol., 2007, 201(8), p 4734-4742

19. B. Zand Naderi and M. Mahdavian, Corrosion and Adhesion Study of Polyurethane Coating on Silane Pretreated Aluminum, Surf. Coat. Technol., 2009, 203(12), p 1677-1681

20. B. Ramezanzadeh, E. Raeisi, and M. Mahdavian, Studying Various Mixtures of 3-Aminopropyltriethoxysilane (APS) and Tetraethylorthosilicate (TEOS) Silanes on the Corrosion Resistance of Mild Steel and Adhesion Properties of Epoxy Coating, Int. J. Adhes. Adhes., 2015, 63, p 166-176

21. M. Pantoja, J. Abenojar, M.A. Martínez, and F. Velasco, Silane Pretreatment of Electrogalvanized Steels: Effect on Adhesive Properties, Int. J. Adhes. Adhes., 2016, 65, p 54-62
22. B. Chico, D. de la Fuente, M.L. Pérez, and M. Morcillo, Corrosion Resistance of Steel Treated with Different Silane/Paint Systems, J. Coat. Technol. Res., 2012, 9(1), p 3-13

23. M.L. Abel, J.F. Watts, and R.P. Digby, The Influence of Process Parameters on the Interfacial Chemistry of $\gamma$-GPS on Aluminium: A Review, J. Adhes., 2004, 80(4), p 291-312

24. T. Titz, F. Hörzenberger, K. Van den Bergh, and G. Grundmeier, Correlation of interfacial electrode potential and corrosion resistance of plasma polymer coated galvanized steel. Part 2: Influence of forming induced defects, Corros. Sci., 2010, 52(2), p 378-386

25. P.R. Seré, C. Deyá, W.A. Egli, C.I. Elsner, and A.R. Di Sarli, Protection of Galvanized Steel with Silanes: Its Comparison with Chromium(VI), J. Mater. Eng. Perform., 2014, 23, p 378-386

26. M. Dattilo, Polarization and Corrosion of Electrogalvanized Steel-Evaluation of Zinc Coatings Obtained from Waste-Derived Zinc Electrolytes, J. Electrochem. Soc., 1985, 132, p 2557-2561

27. J.R. Kearns, J.R. Scully, P.R. Roberge, and J.L. Dawson, Electrochemical Noise Measurements for Corrosion Aplications, ASTM, 1996

28. R.A. Cottis, Interpretation of Electrochemical Noise Data, Corrosion, 2001, 57(3), p 265-285

29. F. Huet, Electrochemical Noise Technique, CRC Taylor \& Francis, Boca Raton, 2005

30. Y.J. Tan, S. Bailey, and B. Kinsella, The Monitoring of the Formation and Destruction of Corrosion Inhibitor Films Using Electrochemical Noise Analysis (ENA), Corros. Sci., 1996, 38(10), p 1681-1695

31. S.S. Jamali and D.J. Mills, A Critical Review of Electrochemical Noise Measurement as a Tool For Evaluation of Organic Coatings, Progr. Org. Coat., 2016, 95, p 26-37

32. F.C. Walsh, C. Ponce de León, C. Kerr, S. Court, and B.D. Barker, Electrochemical Characterisation of the Porosity and Corrosion Resistance of Electrochemically Deposited Metal Coatings, Surf. Coat. Tech., 2008, 202(21), p 5092-5102

33. L. Jiang, M. Wolpers, P. Volovitch, and K. Ogle, An Atomic Emission Spectroelectrochemical Study of Passive Film Formation and Dissolution on Galvanized Steel Treated with Silicate Conversion Coatings, Surf. Coat. Technol., 2012, 206(13), p 3151-3157

34. B. Chico, J.C. Galván, D. de la Fuente, and M. Morcillo, Electrochemical Impedance Spectroscopy Study of the Effect of Curing Time on the Early Barrier Properties of Silane Systems Applied on Steel Substrates, Progr. Org. Coat., 2007, 60(1), p 45-53

35. D. Zhu and W.J. van Ooij, Structural Characterization of bis[triethoxysilylpropyl]tetrasulfide and bis-[trimethoxysilylpropyl]Amine Silanes by Fourier-Transform Infrared Spectroscopy and Electrochemical Impedance Spectroscopy, J. Adhes. Sci. Technol., 2002, 16(9), p 1235-1260

36. A. Franquet, C. Le Pen, H. Terryn, and J. Vereecken, Effect of Bath Concentration And Curing Time on the Structure of Non-functional Thin Organosilane Layers on Aluminium, Electrochim. Acta, 2003, 48(9), p 1245-1255

37. W.J. van Ooij and D. Zhu, Electrochemical Impedance Spectroscopy of Bis-[Triethoxysilypropyl]Tetrasulfide on Al 2024-T3 Substrates, Corrosion, 2001, 57(5), p 413-427

38. B.A. Boukamp, Manual AC-Immittance Data Analysis System "Equivalent Circuit”, Twente University of Technology, Enschede, 1989

39. B.A. Boukamp, Equivalent Circuit AC-Immittance data Analysis System, University of Twente, Enschede, 1993

40. C.X.S.F. Mertens, B.C. Cooman, and E. Temmerman, Short-Term Deterioration Of Polymer-Coated $55 \% \mathrm{Al}-\mathrm{Zn}$-Part 1: Behavior of Thin Polymer Films, Corrosion, 1997, 53, p 381-387 